\title{
Survey of maintenance policies for the Last 50 Years
}

\author{
Asis Sarkar ${ }^{\# 1}$ Dr Subhash Chandra Panja ${ }^{\# 2}$ and Dr Bijan Sarkar ${ }^{\# 3}$ \\ ${ }^{\# 1}$ Department of mechanical Engineering \\ N.I.T.Agartala, P.O.:- t.e.c, Barjala, Agartala: - 799055,(India) \\ \# 2 Department of mechanical Engineering \\ P.O.- Jadavpur University Calcutta:--700032,(India) \\ ${ }^{\# 3}$ Department of Production Engineering \\ P.O:-- Jadavpur University Calcutta:--700032,(India)
}

\begin{abstract}
In the past several decades, maintenance and replacement problems have been extensively studied in the literature. Thousands of maintenance and replacement models have been created. However, all these models can fall into some categories of maintenance policies: age replacement policy, block replacement policy, periodic preventive maintenance policy, failure limit policy, sequential preventive maintenance policy, repair cost limit policy, repair time limit policy, repair number counting policy, reference time policy, mixed age policy, group maintenance policy, opportunistic maintenance policy, etc. Each kind of policy has different characteristics, advantages and disadvantages with lot of contributions from Research scientist, Technologists... This survey summarizes, classifies, and compares various existing maintenance policies Around 170 Authors and their research works are presented in the Reference section. It will help to look into the different policies which is appropriate to the organization and for further study the reference section will be helpful for the researchers for further knowledge
\end{abstract}

Keywords: Maintenance policy; Maintenance; Reliability; Replacement; Optimization

\subsection{INTRODUCTION}

It is well known that the effectiveness of a system depends on both the quality of its design as well as the proper maintenance actions to prevent it from failing. In fact, the choice of scheduled maintenance policies which are optimum from an economic point of view constitutes a predominating approach in reliability theory. A wide and recent study of preventive maintenance models can be found in Ref. [1]. When dealing with maintenance models the features of the failures play a primary role: the classical age and block replacement policies [2] are useful for failures that are detected as soon as they occur (revealed failures); in this situation repairs can be immediately initiated. The opposite case corresponds to unrevealed failures, that is, those, which remain undiscovered unless some kind of inspection or testing is carried out. This usually happens in stored equipment, standby units, or devices that operate rarely as security systems. Badı'a et al. [3] analyzed the existence of a cost optimizing policy within the context of an inspection model which involves corrective maintenance whenever a failure is detected, and having no effect in the unit reliability otherwise. In Ref. [4] a preventive maintenance procedure is considered where inspections and maintenance actions take place at 
different times. Maintenance policies that can be used under unrevealed failures are found in Refs. [5-7,8]

In the past several decades, maintenance and replacement problems have been extensively investigated in the literature. McCall (1963), Barlow and Proshan (1965, 1975), Van Der Duyn Schouten (1996) and Dekker et al. (1997) surveyed and summarized the research and practice in this area in different ways.. This survey is organized into two sections reflecting the classification scheme: maintenance policies of single-unit systems and multi-unit systems. Jensen (1995), Dekker (1996), Pham and Wang (1996), Van Der Duyn Schouten (1996), and Dekker et al. (1997) survey and summarize the research and practice in the maintenance area in different ways. In the survey, a classification scheme of maintenance models that is amenable to current theoretical development is presented. The idea is to classify maintenance models such that a decision maker can recognize the model that best fits his maintenance problem, Hundreds of maintenance models fall into the age replacement policy, and many fall into the failure limit policy. Therefore, this review, surveys existing maintenance models in terms of maintenance policies that they belong to. This survey is organizedinto two sections reflecting the classification scheme: maintenance policies of single-unit systems and multi-unit systems. Since maintenance policies for single-unit systems are more established, and are the basis for maintenance policies of multi-unit systems, this work is focused on single-unit systems. The characteristics, advantages, and drawbacks for each kind of policy will be addressed.

\section{0 Maintenance policies of one-unit systems:}

As mentioned earlier, although thousands of maintenance models have been developed they can be classified into different kinds of maintenance policies. This section summarizes, classifies, and compares maintenance policies of one-unit systems. The characteristics, advantages, and drawbacks for each kind of policy will be addressed. The first five subsections in this section discuss maintenance policies with PMs and another subsection contemplates those without PMs. The last subsection provides a summary of them. The basic assumptions for single-unit systems under all maintenance polices are that the unit lifetime has increasing failure rate (IFR); there are virtually infinitely many disposable identical units with i.i.d. lifetimes; salvage value of the unit is negligible.

2.1. Age-dependent PM policy: The most common and popular maintenance policy might be the age-dependent PM policy. Under this policy, a unit is always replaced at its age T or failure, whichever occurs first, where $\mathrm{T}$ is a constant (Barlow and Hunter, 1960). The concepts of minimal repair or imperfect maintenance (Pham and Wang, 1996) were established.. Details of age replacement policy can be found in Pham and Wang (1996), and Valdez-Flores and Feldman (1989). If $\mathrm{T}$ is a random variable, the policy is referred to as the random agedependent maintenance policy. Tahara and Nishida (1975) introduce the maintenance policy "replace the unit when the first failure after t 0 hours of operation or when the total operating time reaches $\mathrm{T}(0 \leq \mathrm{t} 0 \leq \mathrm{T})$ whichever occurs first; Failures in $(0, \mathrm{t} 0)$ are removed by minimal repair" Note that if $\mathrm{t} 0=0$, it becomes the age replacement policy, and if $\mathrm{t} 0=\mathrm{T}$ it reduces to the "periodic replacement with minimal repair at failure" policy. Observe that t0 is a reference time and maintenance actions are not performed exactly at that moment t0 (unlike PM time). Nakagawa (1984) extends the age replacement policy to replacing a unit at time $\mathrm{T}$ or at number $\mathrm{N}$ of failures, whichever occurs first, and undergoes minimal repair at failure between replacements. The decision variables for this policy are $\mathrm{T}$ and $\mathrm{N}$. In this policy, if $\mathrm{N}=1$, this policy reduces to the age replacement policy. Herein this policy is called $\mathrm{T}-\mathrm{N}$ policy.. Wang and Pham (1999) make another extension of age replacement policy, called "mixed age PM 
policy'. In this policy, after $\mathrm{n}$ th imperfect repair, there are two types of failures. A type 1 failure might be total breakdowns, while another type 2 failure can be interpreted as a slight and easily fixed problem. When a failure occurs, it is a type 1 failure with probability $p(t)$ and a type 2 failure with probability $q(\mathrm{t})=1-\mathrm{p}(\mathrm{t})$. After the first $\mathrm{n}$ imperfect repairs, the unit will be subject to a perfect maintenance at age $\mathrm{T}$ or at the first type 1 failure, whichever occurs first. The policy decision variables are $T$ and $n$. If $p(t)=0$ and $n=0$ it becomes periodic replacement with minimal repair at failure policy. So if $\mathrm{p}(\mathrm{t})=1$ and $\mathrm{n}=0$, it becomes the age replacement policy. Studies on the age-dependent PM policy went back to as early as Morse (1958). Various age-dependent PM policies, are summarized and are listed in Table 1.

2.2. Periodic PM policy: In the periodic PM policy, a unit is preventively maintained at fixed time intervals $\mathrm{kT}(\mathrm{k}=1,2---)$ independent of the failure history of the unit, and repaired at intervening failures $\mathrm{T}$ where $\mathrm{T}$ is a constant. In the block replacement policy a unit is replaced at prearranged times $\mathrm{kT}(\mathrm{k}=1,2-----)$ and at its failures. The block replacement policy derives its name from replacing a block or group of units in a system at prescribed times $\mathrm{kT}(\mathrm{k}=1,2----$ --) independent of the failure history of the system and is

Table 1: Summary of age-dependent PM policies

\begin{tabular}{|c|c|c|c|c|}
\hline Policy & $\begin{array}{l}\text { Typical } \\
\text { reference }\end{array}$ & PM time points & $\begin{array}{l}\text { Decision } \\
\text { variables }\end{array}$ & Special cases \\
\hline $\begin{array}{l}\text { Age } \\
\text { replacement }\end{array}$ & $\begin{array}{l}\text { Barlowand } \\
\text { Hunter(1960) }\end{array}$ & Fixed age $T$ & $\mathrm{~T}$ & \\
\hline $\begin{array}{l}\text { Repair } \\
\text { replacement }\end{array}$ & $\begin{array}{l}\text { Block et al. } \\
(1993)\end{array}$ & $\begin{array}{l}\text { Time since last } \\
\text { maintenance }\end{array}$ & Fixed time & Age replacement \\
\hline $\mathrm{T}-\mathrm{N}$ & $\begin{array}{l}\text { Nakagawa } \\
(1984)\end{array}$ & $\begin{array}{l}\text { Fixed age } \mathrm{T} \text { or } \\
\text { time }\end{array}$ & $\mathrm{T}, \mathrm{N}$ & $\begin{array}{l}\text { Age replacement } \\
\text { periodic PM }\end{array}$ \\
\hline $\mathrm{T}, \mathrm{t}$ & $\begin{array}{lll}\begin{array}{l}\text { Sheu } \\
(1993)\end{array} & \text { et } & \text { al. }\end{array}$ & $\begin{array}{l}\text { Fixed age } \mathrm{T} \text { or } \\
\text { time }\end{array}$ & $\mathrm{T}, \mathrm{t}$ & $\begin{array}{l}\text { Age replacement } \\
\text { periodic } \mathrm{PM}\end{array}$ \\
\hline $\mathrm{t} 0, \mathrm{~T}$ & $\begin{array}{l}\text { Taharaand } \\
\text { Nishida(1975) } \\
\end{array}$ & Fixed age & $\mathrm{t} 0, \mathrm{~T}$ & $\begin{array}{l}\text { Age replacement } \\
\text { periodic PM }\end{array}$ \\
\hline Mixed age & $\begin{array}{l}\text { Wang and Pham } \\
\text { (1999) }\end{array}$ & $\begin{array}{l}\text { Fixed age } \mathrm{T} \text { or } \\
\text { time }\end{array}$ & $\mathrm{k}, \mathrm{T}$ & $\begin{array}{l}\text { Age replacement } \\
\text { periodic PM }\end{array}$ \\
\hline $\mathrm{T}, \mathrm{n}$ & $\begin{array}{lll}\text { Sheu } & \text { et } & \text { al. } \\
(1995) & & \end{array}$ & Fixed age $\mathrm{T}$ & $\mathrm{T}, \mathrm{n}$ & $\begin{array}{l}\text { Age replacement } \\
\text { periodic } \mathrm{PM}\end{array}$ \\
\hline
\end{tabular}

often used for multi-unit systems. Another basic PM periodic policy in this class is "periodic replacement with minimal repair at failures" policy under which a unit is replaced at predetermined times $\mathrm{kT}(\mathrm{k}=1,2-------------)$ and failures are removed by minimal repair (Barlow and Hunter, 1960, Policy II). One expansion of the "periodic replacement with minimal repair at failure" policy is the one where a unit receives imperfect PM every T time unit, intervening failures are subject to minimal repairs, and it is replaced after its age has reached $(\mathrm{O}+1) \mathrm{T}$ time units, where $\mathrm{O}$ is the number of imperfect PMs which have been done (Liu et al., 1995). The policy decision variables are $\mathrm{O}$ and T. If $\mathrm{O}=0$, this policy becomes the "periodic replacement with minimal repair at failure" policy. Berg and Epstein (1976) have modified the block replacement policy by setting an age limit. Under this modified policy, a failed unit is replaced by a new one; however, units whose ages are less than or equal to t0 ( $0 \leq$ $\mathrm{t} 0 \leq \mathrm{T})$ at the scheduled replacement times $\mathrm{kT}(\mathrm{k}=1,2------------)$ are not replaced, but 
remain working until failure or the next scheduled replacement time point. Obviously, if $\mathrm{t} 0=\mathrm{T}$ , it reduces to the block replacement policy. This modified block replacement policy was shown to be superior to the block replacement policy in terms of the long-run maintenance cost rate.Tango (1978) suggests that some failed units be replaced by used ones, which have been collected before the scheduled replacement times. Under this extended block replacement policy, units are replaced by new ones at periodic times $\mathrm{kT},(\mathrm{k}=1,2-------------)$ The failed units are, however, replaced by either new ones or used ones based on their individual ages at the times of failures. A time limit $r$ is set in this policy, similar to t0 in Berg and Epstein (1976). If a failed unit' age is less than or equal to a predetermined time limit $r$, it is replaced by a new one; otherwise, it is replaced by a used one. Obviously, if $\mathrm{r}=\mathrm{T}$, this policy becomes the block replacement policy. Nakagawa (1981) presents three modifications to the "periodic replacement with minimal repair at failure" policy.The three policies all establish a reference time $\mathrm{T} 0$ and periodic time $\mathrm{T}^{*}$. If failure occurs before $\mathrm{T} 0$, then minimal repair occurs. If the unit is operating at time $\mathrm{T}^{*}$, then replacement occurs at time $\mathrm{T}^{*}$. If failure occurs between $\mathrm{T} 0$ and $\mathrm{T} *$, then: (Policy I) the unit is not repaired and remains failed until $\mathrm{T}^{*}$; (Policy II) the failed unit is replaced by a spare unit until T* ; (Policy III) the failed unit is replaced by a new one. In all these three policies, the policy decision variables are $\mathrm{T} 0$ and $\mathrm{T}^{*}$. Clearly, if $\mathrm{T} 0=\mathrm{T}^{*}$ , Policies I, II, and III all become the "periodic replacement with minimal repair at failure" policy. If T0 $=0$, Policy III becomes the block replacement policy. Nakagawa (1980) also makes an expansion to the block replacement policy. In his policy, a unit is replaced at times kT kT ( $k=1,2-----------)$ independent of the age of the unit. A failed unit remains failed until the next planned replacement. Another variant of the "periodic replacement policy with minimal repair" policy is also due to Nakagawa (1986), in which the replacement is scheduled at periodic times $\mathrm{kT}(\mathrm{k}=1,2-------------)$ and failure is removed by minimal repair. If the total number of failures is equal to or greater than a specified number $\mathrm{n}$, the replacement should be done at the next scheduled time; otherwise, no maintenance should be done. The decision variable is $\mathrm{n}$ and $\mathrm{T}$. In this policy, if $\mathrm{n}=\infty$, this policy becomes the "periodic replacement with minimal repair at failure" policy. Chun (1992) studies determination of the optimal number of periodic PM's under a finite planning horizon. Dagpunar and Jack (1994) determine the optimal number of imperfect PMs for a finite horizon given that the minimal repair is made at any failure between PM's. Wang and Pham (1999) extend the block replacement policy to a general case. In their policy, a unit is imperfectly repaired at failure if the number of repairs is less than $\mathrm{N}$ (a positive integer). The repair is imperfect in the sense that the unit has shorter lifetime upon each repair. Upon the Nth imperfect repair at failure, the unit is preventively maintained at kT ( $\mathrm{k}=1,2$----------) where the constant $\mathrm{T}>0 .$. If the repair at failure and PM are perfect and $\mathrm{N}=\infty$, this policy reduces to the block replacement policy.. Maintenance schedules under the periodic PM policy are summarized in Table 2.

2.3. Failure limit policy : Under the failure limit policy, PM is performed only when the failure rate or other reliability indicesof a unit reach a predetermined level and intervening failures are corrected by repairs. This PM policy makes a unit work at or above the minimum acceptable level of reliability. For example, Lie and Chun (1986) formulate a maintenance cost policy where PM is performed whenever a unit reaches the predetermined maximum failure rate, and failures are corrected by minimal repair. Bergman (1978) investigates a failure limit policy in which replacement policies are based on measurements of some increasing state variable 
International Journal of Software Engineering \& Applications (IJSEA), Vol.2, No.3, July 2011

Table 2 Summary of periodic PM policies

\begin{tabular}{|c|c|c|c|c|}
\hline Policy & $\begin{array}{l}\text { Typical } \\
\text { reference }\end{array}$ & PM time points & Decision variables & Special cases \\
\hline $\begin{array}{l}\text { Block } \\
\text { replacement }\end{array}$ & $\begin{array}{l}\text { Barlow and } \\
\text { Hunter (1960) }\end{array}$ & Periodic time & Periodic time & \\
\hline $\begin{array}{l}\text { Periodic } \\
\text { replacement } \\
\text { with } \\
\text { minimal } \\
\text { repair }\end{array}$ & $\begin{array}{l}\text { Barlow and } \\
\text { Hunter (1960) }\end{array}$ & Periodic time & Periodic time & \\
\hline $\begin{array}{l}\text { Overhaul } \\
\text { and minimal } \\
\text { repair }\end{array}$ & Liu et al. (1995) & $\begin{array}{lr}\text { Periodic } & \text { time } \\
\text { and } & \text { its } \\
\text { multiples } & \\
\end{array}$ & $\begin{array}{l}\text { Fixed number } \\
\text { ofPMs/periodic time }\end{array}$ & $\begin{array}{l}\text { Periodic replacement } \\
\text { with minimal repair }\end{array}$ \\
\hline $\begin{array}{l}(\mathrm{T} 0 ; \mathrm{T} \quad) \\
\text { Policy I }\end{array}$ & $\begin{array}{l}\text { Nakagawa } \\
(1981 a, b)\end{array}$ & Periodic time & $\begin{array}{l}\text { Periodic time/ reference } \\
\text { time }\end{array}$ & $\begin{array}{l}\text { Periodic } \\
\text { replacementwith } \\
\text { minimal repair }\end{array}$ \\
\hline $\begin{array}{l}(\mathrm{T} 0 ; \quad \mathrm{T} \quad) \\
\text { Policy II }\end{array}$ & $\begin{array}{l}\text { Nakagawa } \\
(1981 a, b)\end{array}$ & Periodic time & $\begin{array}{l}\text { Periodic } \\
\text { replacementwith } \\
\text { minimal repair }\end{array}$ & $\begin{array}{l}\text { Periodic } \\
\text { replacementwith } \\
\text { minimal repair/ Block } \\
\text { replacement }\end{array}$ \\
\hline $\begin{array}{l}\text { (T0; } \quad \text { T } \\
\text { Policy III }\end{array}$ & $\begin{array}{l}\text { Nakagawa } \\
(1981 a, b)\end{array}$ & Periodic time & $\begin{array}{l}\text { Periodic time/reference } \\
\text { time }\end{array}$ & $\begin{array}{l}\text { Periodic } \\
\text { replacementwith } \\
\text { minimal repair/ Block } \\
\text { replacement }\end{array}$ \\
\hline $\mathrm{n}, \mathrm{T}$ & $\begin{array}{l}\text { Nakagawa } \\
(1986)\end{array}$ & Periodic time & $\begin{array}{l}\text { Periodic time/number of } \\
\text { failures }\end{array}$ & $\begin{array}{l}\text { Periodic } \\
\text { replacementwith } \\
\text { minimal repair }\end{array}$ \\
\hline $\mathrm{r}, \mathrm{T}$ & Tango (1978) & Periodic time & $\begin{array}{l}\text { Periodic time/reference } \\
\text { age }\end{array}$ & Block replacement \\
\hline $\mathrm{N}, \mathrm{T}$ & $\begin{array}{l}\text { Wang and Pham } \\
\text { (1999) }\end{array}$ & $\begin{array}{lr}\text { Periodic } & \text { time } \\
\text { and } & \text { its } \\
\text { multiples } & \end{array}$ & $\begin{array}{l}\text { Periodic time/number of } \\
\text { repairs }\end{array}$ & $\begin{array}{l}\text { Block replacement/ } \\
\text { periodic replacement } \\
\text { with minimal repair }\end{array}$ \\
\hline $\mathrm{t} 0, \mathrm{~T}$ & $\begin{array}{l}\text { Berg and } \\
\text { Epstein (1976) }\end{array}$ & Periodic time & $\begin{array}{l}\text { Periodictime/reference } \\
\text { age }\end{array}$ & Block replacement \\
\hline
\end{tabular}

state variable, e.g., wear, accumulated damage or accumulated stress, and the proneness to failure of an active unit is described by an increasing state dependent failure rate function. The optimal replacement rule in terms of average long-run maintenance cost rate is shown to be a failure limit rule, i.e., it is optimal to replace either at failure or when the state variable has reached some threshold value, whichever occurs first. Bergman's model includes the age replacement policy as a special case. Other research on the failure limit policy can be found in Malik (1979), Canfield (1986), Jayabalan and Chaudhuri (1992a), Jayabalan and Chaudhuri (1992c), Jayabalan and Chaudhuri (1995), Chan and Shaw (1993), Suresh and Chaudhuri (1994), Monga et al. (1997), Pham and Wang (1996). In addition, Love and Guo (1996) study failure limit policy for PM decisions under Weibull failure rates. Generally, the problem of this class of policy is that it requires much computing efforts. The failure limit policy and its extensions are summarized in Table 3.

2.4. Sequential PM policy: Unlike the periodic PM policy, a unit is preventively maintained at unequal time intervals under the sequential PM policy.. An early sequential PM policy is 
designed for a finite span (Barlow and Proshan, 1965). Under this sequential policy, the age for which PM is scheduled is no longer the same following successive PMs, but depends on the time still remaining. Under sequential PM, the next PM interval is selected to minimize the expected expenditure during the remaining time. Nguyen and Murthy (1981) introduce a sequential policy which calls for a PM if a failure has not occurred by some reference time ti, where ti, is the maximum time that a unit should be left without maintenance after the (i_ 1$)$ th repair (time from the last repair or replacement). In this policy, a unit is replaced after (k-1) th repairs. It is repaired (or replaced at the $\mathrm{k}$ th repair) at the time of failure or at age ti, whichever occurs first. The decision variables are $\mathrm{k}$ and $\mathrm{ti}$, for $\mathrm{i}=1 \ldots$; given that each PM increases the failure rate of the unit. If $\mathrm{k}=1$, this sequential policy reduces to the age replacement policy. Nakagawa $(1986,1988)$ discusses a sequential PM policy where PM is done at fixed intervals $\mathrm{Xk}$

Table 3 Summary of failure limit policies

\begin{tabular}{|c|c|c|c|}
\hline Typical reference & $\begin{array}{ll}\text { Reliability } & \text { index } \\
\text { monitored }\end{array}$ & $\begin{array}{l}\text { Optimality } \\
\text { criterion }\end{array}$ & Planning horizon \\
\hline Bergman (1978) & $\begin{array}{l}\text { Failure rate through wear/ } \\
\text { accumulated damage or } \\
\text { stress }\end{array}$ & Cost rate & Infinite \\
\hline Malik (1979) & Reliability & Reliability & Infinite \\
\hline Canfield (1986) & Failure rate & Cost rate & Infinite \\
\hline Zheng and Fard (1991) & Failure rates & Cost rate & Infinite \\
\hline Lie and Chun (1986) & Failure rate & Cost rate & Infinite \\
\hline $\begin{array}{l}\text { Jayabalan and } \\
\text { Chaudhuri (1992a) }\end{array}$ & Failure rate & Total cost & Finite \\
\hline $\begin{array}{l}\text { Jayabalan and } \\
\text { Chaudhuri (1992c) }\end{array}$ & Age others & Cost rate & Infinite \\
\hline $\begin{array}{l}\text { Jayabalan and } \\
\text { Chaudhuri (1992d) }\end{array}$ & Age & Total cost & Finite \\
\hline Chan and Shaw (1993) & Failure rate & Availability & Infinite \\
\hline $\begin{array}{l}\text { Suresh and Chaudhuri } \\
\text { (1994) }\end{array}$ & Reliability and failure rate & Total cost & Finite \\
\hline $\begin{array}{ll}\text { Jayabalan } & \text { and } \\
\text { Chaudhuri (1995) }\end{array}$ & Age & Total cost & Finite \\
\hline Monga et al. (1997) & $\begin{array}{l}\text { Reduction (age and failure } \\
\text { rate) }\end{array}$ & Cost rate & Infinite \\
\hline Love and Guo (1996) & Weibull failure rate & Cost rate & Infinite \\
\hline
\end{tabular}

for $\mathrm{k}=1 ; 2 ;$; . N. The unit is replaced at the Nth PM and failures between PMs are corrected by minimal repairs, given the unit has different failure distributions between PMs (the failure rate of theunit increases with the number of PMs, or its age is reduced (1988), i.e., the first (N 1) PMs are imperfect). The policy decision variables are $\mathrm{N}$ and $\mathrm{Xk} k=1,2 \ldots$ N. Nakagawa $(1986,1988)$ also presents two numerical examples indicating that the optimal policy satisfies $\mathrm{Xk} \leq \mathrm{Xk}-1$, for $\mathrm{k}=2$. Nguyen and Murthy (1981) study this policy (Policy II in their paper). If $\mathrm{N}=1$, this Sequential policy reduces to the "periodic replacement with minimal repair at failure" policy. They are different from the failure limit policy in that it controls Xk lengths directly but the failure limit policy controls failure rate, reliability, etc., directly. Moreover, 
Kijima and Nakagawa (1992) develop a sequential PM policy using an accumulated damage concept.

2.5. Repair limit policy: When a unit fails, the repair cost is estimated and repair is undertaken if the estimated cost is less than a predetermined limit; otherwise, the unit is replaced. This is called the repair cost limit policy, as introduced by Gardent and Nonant (1963), and Drinkwater and Hastings (1967). Beichelt (1982) examines repair cost limit policy and uses the repair cost rate (repair cost per unit time) as a criterion of replacement or repair: a unit is replaced as soon as the repair cost rate reaches or exceeds a fixed level, otherwise, it is repaired. Yun and Bai (1987) propose a repair cost limit policy in which when a unit fails, the repair cost is estimated and repair is undertaken if the estimated cost is less than a predetermined limit L, where the repair is imperfect. otherwise, the unit is replaced. This policy by Yun and Bai (1987) is generalized from the one by Drinkwater and Hastings (1967.The repair time limit policy is proposed by Nakagawa and Osaki (1974) in which a unit is repaired at failure: if the repair is not completed within a specified time $\mathrm{T}$, it is replaced by a new one; otherwise the repaired unit is put into operation again, where $T$ is called repair time limit. Nguyen and Murthy (1980) study a repair time limit replacement policy with imperfect repair in which there are two types of repair - local and central repair. The local repair is imperfect while the central repair is perfect, which may take a longer time. Dohi et al., 1997 consider a generalized repair time limit replacement problem with lead time and imperfect repair, which is subject to a time constraint, and propose a nonparametric solution procedure to estimate the optimal repair time limit. Koshimae et al. (1996) consider another repair time limit policy. Under this policy, when the original unit fails, the repair is started immediately. If the repair is completed in a time limit t0, then the repaired unit is installed as soon as the repair is finished. On the other hand, if the repair time is greater than the time limit $\mathrm{t} 0$, the failed unit is scrapped and a spare is ordered immediately. It is delivered and installed after a lead time. The policy decision variable is the repair time limit t0.The repair limit policy and its extensions are summarized in Table 4.

2.6. Repair number counting and reference time policy: Morimura and Makabe (1963) introduce a policy where a unit is replaced at the kth failure. The first k-1 failures are removed by minimal repair. Upon replacement, the process repeats. This policy is called repair number counting policy. The policy decision variable is k. Later, Morimura (1970) extends this policy by introducing another policy variable $\mathrm{T}$ critical reference time. Under this policy, all failures before the kth failure are corrected only with minimal repair. If the kth failure occurs before an accumulated operating time $\mathrm{T}$, it is corrected by minimal repair and the next failure induces replacement. But if the kth failure occurs after $\mathrm{T}$, it induces replacement of the unit. The policy decision variables are $\mathrm{k}$ and $\mathrm{T}$. If the policy decision variable $\mathrm{T}$ is zero, this policy reduces to the repair number counting policy. The repair number counting policy is examined by Jack (1991): performing imperfect repair on failure, and replacement upon the kth failure. A policy similar to the repair number counting policy is also investigated by Park (1979) in which a unit is replaced at the kth failure and minimal repairs are performed for the first(k-1)th failures. Later, Lam (1988), and Stadje and Zuckerman (1990) investigate the repair number counting policy, given that the lengths of the operating intervals decrease whereas the durations of the repair increase in different ways. Muth (1977) examines a replacement policy, similar to the reference time idea of the extended policy by Morimura (1970), in which a unit is minimally repaired up to time $\mathrm{T}$ and replaced at the first failure after $\mathrm{T}$. This policy is referred to as reference time policy. Note that in this policy the maintenance action is not undertaken exactly at the reference time point T (unlike PM time).. Makis and Jardine (1992) introduce a general 
policy in which a unit can be replaced at any time and at the nth failure the unit can be either replaced or can undergo an imperfect repair. Under different conditions, this policy can reduce to the repair number counting policy, reference time policy, and "periodic replacement with minimal repair at failure" policy, respectively. . In general, the repair number counting policy is effective when the total operating time of a unit is not recorded or it is time consuming and costly to replace a unit in operation In the positive aging, the unit deteriorates and eventually reaches

\section{Table 4 Summary of repair limit policies}

\begin{tabular}{|l|l|l|l|l|l|}
\hline Reference & $\begin{array}{l}\text { CM before } \\
\text { limit }\end{array}$ & $\begin{array}{l}\text { CM after } \\
\text { limit }\end{array}$ & Limit & $\begin{array}{l}\text { Optimality } \\
\text { criterion }\end{array}$ & $\begin{array}{l}\text { Planning } \\
\text { horizon }\end{array}$ \\
\hline Hastings (1969) & Minimal & Perfect & Cost & Cost rate & Infinite \\
\hline Kapur et al. (1989) & Minimal & Perfect & Cost & Cost rate & Infinite \\
\hline Beichelt (1982) & Perfect & Perfect & Cost rate & Cost rate & Infinite \\
\hline Beichelt (1981a,b) & Minimal & Perfect & Cost rate & Cost rate & Infinite \\
\hline $\begin{array}{l}\text { Nguyen and Murthy } \\
\text { (1980) }\end{array}$ & Imperfect & Perfect & Time & Cost rate & Infinite \\
\hline Yun and Bai (1988) & Minimal & Perfect & Cost & Cost rate & Infinite \\
\hline $\begin{array}{l}\text { Koshimae et al. } \\
\text { (1996) }\end{array}$ & Perfect & Perfect & Time & Cost rate & Infinite \\
\hline $\begin{array}{l}\text { Nguyen and Murthy } \\
\text { (1980) }\end{array}$ & Minimal & Perfect & Time & Cost rate & Infinite \\
\hline Dohi et al. (1997) & Minimal & Imperfect & Time & Cost rate & Infinite \\
\hline Park (1979) & Minimal & Perfect & Cost & Cost rate & Infinite \\
\hline $\begin{array}{l}\text { Nakagawa and } \\
\text { Osaki (1974) }\end{array}$ & Minimal & Perfect & Time & Cost rate & Infinite \\
\hline Yun and Bai (1987) & Imperfect & Perfect & Cost & Cost rate & Infinite \\
\hline $\begin{array}{l}\text { Wang and Pham } \\
\text { (1996d) }\end{array}$ & Imperfect & Imperfect & Cost & $\begin{array}{l}\text { Availability/cost } \\
\text { rate }\end{array}$ & Infinite \\
\hline
\end{tabular}

a condition where it is no longer economically justifiable to perform minimal repair after repair. Phelps (1981) compares the "periodic replacement with minimal repair at failure" policy (Barlow and Hunter, 1960), the repair number counting policy (Morimura and Makabe, 1963,Park, 1979), and the reference time policy (Muth, 1977), given an increasing failure rate. Phelps (1981) shows that the reference time policy, replacing after the first failure that occurs after reference time $\mathrm{T}$, is the optimal of the three policies in terms of the long-run cost rate; The repair number counting policy is more economical than the "periodic replacement with minimal repair at failure" policy. Note that generally there are no PMs scheduled for this type of policy. These policies are mainly based on counting the number of repairs and/or reference time, but the age-dependent PM policy and periodic PM policy rely on PM times, at which maintenance actions are performed. In the repair number counting and reference time policy, maintenance actions are not undertaken precisely at the reference time point $T$. In the repair number counting and reference time policy, number of repairs and/or reference time are policy decision variable(s). In the age-dependent PM policy and periodic PM policy, PM time is one of the policy decision variables.

2.7. On the maintenance policies for single-unit systems : The age-dependent PM policy and periodic PM policy have received much more attention in the literature. Hundreds of papers 
and models have been published (McCall (1963), Barlow and Proshan (1965, 1975), Pierskalla and Voelker (1976), Osaki and Nakagawa (1976), Sherif and Smith (1981), Pham and Wang (1996)) under these two kinds of maintenance policies. Detailed comparisons on the age and block replacement policies can be found in Barlow and Proshan $(1965,1975)$ in which the general conclusion is that the age replacement policy is an economical way to the block replacement policy. Berg and Epstein (1978) compare three types of replacement policies: age, block, failure replacement policies and provided a heuristic rule for choosing the best one. In Block et al. (1990), comparisons are made between the block replacement policy and "periodic replacement with minimal repair at failure" policy. In Block et al. (1993), comparisons are made among the age replacement policy, block replacement policy, and repair replacement policy. The failure limit policy, repair limit policy, and sequential policy are more practical, but there has been much less research done on it. The failure limit policy is also directly consistent with the maintenance objectives: improving reliability and reducing failure frequency. One of the disadvantages of the failure limit policy and sequential policy is that their PM intervals are not equal and thus it is wasteful to implement them. The periodic PM policy is perhaps more practical than the age-dependent PM policy since it does not require keeping records on unit usage. The block replacement policy is more wasteful than the age replacement policy since a unit of "young" age might be replaced at periodic timesThe maintenance policies have become more and more general because they include some previous policies as special cases. This is reflected in Tables 1 and 2,. In general, optimal maintenance plans obtained from these general policies may result in some cost savings since the optimal maintenance schedules under them might be "globally" optimal (optimal in a larger range). The maintenance cost may be a function of unit age and number of repairs already performed on the unit (It is noted that Frenk et al. (1997) establish a general method for modeling complicated maintenance costs, which is also convenient for this case). The current research seems to intend to use two or more of them as policy decision variables in a single policy.

\section{Maintenance policies of multi-unit systems:}

Multi unit systems are those system with a number of subsystems. Optimal maintenance policies for such systems reduce to those for systems with a single subsystem only if there exists neither economic dependence, failure dependence nor structural dependence. In this case, maintenance decisions are independent, and the "optimal" maintenance policy is to employ one of the six classes of maintenance policies for each separate subsystem. The optimal maintenance action for a given subsystem at any time point depends on the states of all subsystems in the system: the failure of one subsystem results in the possible opportunity to undertake maintenance on other subsystems (opportunistic maintenance).. Failure dependence means that failure distributions of several subsystems are stochastically dependent. Economic dependency is common in most continuous operating systems. For this type of system, the cost of system unavailability (onetime shut-down) may be much higher than maintenance costs. Therefore, there is often a great potential for cost savings by implementing an opportunistic maintenance policy. Currently, there is an increasing interest in multicomponent maintenance policies and models. As pointed out in Van Der Duyn Schouten (1996), one of the reasons that is often put forward to explain the lack of success in applications of maintenance and replacement models is the simplicity of the models compared to the complex environment where the applications occur. In particular, the fact that up to 10 years ago the vast majority of the maintenance models were concerned with one single piece of equipment operating in a fixed environment was considered as an intrinsic barrier for applications. Next we summarize maintenance policies for multi-unit systems. Cho and Parlar (1991) survey the multi-unitsystem 
maintenance models created before 1991, and Dekker et al.'s review is focused on economic dependence models published after 1991 (cf. Dekker et al., 1997). This survey is emphasized on classifications and characteristics of maintenance policies though sometimes it cites the same existing maintenance models as the previous surveys. The basic assumptions for multiunit systems under all maintenance police are that there are virtually infinitely many disposable identical units with i.i.d. lifetimes for all items; salvage values of all units are negligible.

3.1. Group maintenance policy : The problem of establishing group maintenance policies, which are best from the point of view of the system's reliability or operational cost, has received significant attention. One class of problem for group maintenance policies has been to establish categories of units that should be replaced when a failure occurs. A second class of group replacement studies has been concerned with reducing costs by including redundant parts into systems design. A third class of papers has been concerned with for systems of independently operating machines, all of which are subject to stochastic failures (Ritchken and Wilson, 1990). For this class of problems, there are three existing group maintenance policies. The first policy, referred to as a Tage group replacement policy, calls for a group replacement when the system is of age T. A second policy, referred to as an m-failure group replacement policy, calls for a system inspection after $\mathrm{m}$ failures have occurred. The third policy combines the advantages of the $\mathrm{m}$-failure and T-age policies. This policy, referred to as an $(\mathrm{m}, \mathrm{T})$ group replacement policy, calls for a group replacement when the system is of age $T$, or when $m$ failures have occurred, whichever comes first. The $(\mathrm{m}, \mathrm{T})$ group replacement policy requires inspection at either the fixed age $\mathrm{T}$ or the time when $\mathrm{m}$ machines have failed, whichever comes first. At an inspection, all failed units are replaced with new ones and all functioning units are serviced so that they become as good as new.. Gertsbakh (1984) introduces a policy in which a system has $\mathrm{n}$ identical units with exponential lifetimes, and it is repaired when the number of failed units reaches some prescribed number $\mathrm{k}$, the policy decision variable. Vergin and Scriabin (1977) propose a (n,N) policy. Love et al. (1982) establish another group replacement policy for a fleet of vehicles. Under this group maintenance policy a vehicle is replaced when repair cost for the vehicle exceeds a pre-set repair limit; otherwise, it is repaired. Sheu and Jhang (1997) propose a 2-phase group maintenance policy for a group of identical repairable items. The time interval $(0 ; \mathrm{T}]$ is defined as the first phase, and the timer interval $(\mathrm{T} ; \mathrm{T}+\mathrm{W}]$ is defined as the second phase. As individual units fail, individual units have two types of failures. Type I failures are removed by minimal repairs, whereas Type II failures are removed by replacements or are left idle. A group of maintenance is conducted at time $\mathrm{T}+\mathrm{W}$ or upon the kth idle, whichever comes first.

3.2. Opportunistic maintenance policies ; As pointed out earlier, maintenance of a multicomponent system differs from that of a single unit system because there exists dependence in multicomponent systems. One of the dependencies is economic dependence. Another dependence is failure dependence, or correlated failures. (Nakagawa and Murthy, 1993). Berg (1976, 1978), suggests a preventive replacement policy for a machine with two identical components which are subject to exponential failure. Under this policy, upon a component failure the other component as well as the failed one is also replaced by a new one if its age exceeds a pre-determined control limit L. Later, Berg (1978) extends it to such an policy: both units are replaced either when one of them fails and the age of the other unit exceeds the critical control limit L, or when any of them reaches a predetermined critical age S. A unit is replaced at age $\mathrm{T}$ or at failure, This policy will become two independent age replacement policies if $\mathrm{L}=\infty$. Zheng and Fard (1991) examine an opportunistic maintenance 
policy based on failure rate tolerance for a system with $\mathrm{k}$ different types of units. A unit is replaced (active replacement) either when the hazard rate reaches $L$ or at failure with the failure rate in a predetermined interval L-u, L.. Kulshrestha (1968) investigates an opportunistic maintenance policy in which there are two classes of units, 1 and 2. Class 1 contains M standby redundant units so that upon the failure of the currently operating class- 1 units, a standby takes over. When all the class- 1 standbys have failed, the system suffers catastrophic failure. The class- 2 units, on the other hand, form a series system; if one of them should fail, the system suffers a minor breakdown. When a minor breakdown occurs, there is a possible chance for opportunistic repair of those class-1 units which have failed. Pham and Wang (2000) propose two new $(\tau, \mathrm{T})$ opportunistic maintenance policies for a k-out-of $\mathrm{n}$ system. In these two policies, minimal repairs are performed on failed components before time $\tau$ - a policy decision variable, and $\mathrm{CM}$ of all failed components is combined with PM of all functioning ones after $\tau$.At time $\mathrm{T}$, another policy decision variable, PM is performed if the system has not been subject to a perfect maintenance before $\mathrm{T}>\tau$. The policy decision variables are $\tau$ and $\mathrm{T}$. Pham and Wang (2000) also extend these two policies to the one including the third decision variable the number of failed components to start CM, considering the k-out-of-n system may still operate even if some of its components have failed. Dagpunar (1996) introduces a general maintenance policy where replacement of a component within a system is available at an opportunity. Rander and Jorgenson (1963), and Wang (2001) investigate an opportunistic preparedness maintenance of multi-unit systems with $(n+1)$ subsystems. Wang. (2001) examine such a preparedness policy: If subsystem i fails when the age of subsystem 0 is in the time interval $(0$, ti ) replace subsystem $\mathrm{i}$ alone at a cost of $\mathrm{Ci}$ and at a time of $\mathrm{Wi} \mathrm{i}=1,2 \ldots \mathrm{N}$

(i)If subsystem $\mathrm{i}$ fails when the age of subsystem 0 is in the time interval( $\mathrm{ti} T$ ) replace subsystem $\mathrm{i}$ and do perfect PM on subsystem $0(\mathrm{i}=1,2 \ldots \mathrm{N})$ The total maintenance cost is $\mathrm{CO} \mathrm{i}$ and total maintenance time is w0i

(ii)If subsystem 0 survives until its age $\mathrm{x}=\mathrm{T}$ perform $\mathrm{PM}$ on subsystem 0 alone at a and a maintenance time of $\mathrm{w} 0$ at $\mathrm{x}=\mathrm{T} \mathrm{PM}$ is imperfect.

(iii) If subsystem 0 has not received a perfect PM at T, perform PM on it alone at time $\mathrm{jT}(\mathrm{j}$ $=2,3 \ldots$. .) until it gets a perfect PM; If subsystem $\mathrm{O}$ has not experienced a perfect maintenance and subsystem i fails after some PM, replace subsystem i and do perfect PM on subsystem 0 (i $=1,2 \ldots \mathrm{N})$ The total maintenance cost is still $\mathrm{C} 0 \mathrm{i}$ and total maintenance time is W0i This process continues until subsystem 0 gets a perfect maintenance.

\section{Optimal maintenance policies :}

Maintenance aims to improve system availability and MTBF, to reduce failure frequency and downtime. However, since maintenance incurs cost, to reduce maintenance cost is also necessary. Generally, an optimal system maintenance policy may be the one which either

(a) minimizes system maintenance cost rate,

(b) maximizes the system reliability measures,

(c) minimizes system maintenance cost rate while the system reliability requirements are satisfied, or

(d) maximizes the system reliability measures when the requirements for the system maintenance cost are satisfied. Fig. 1 shows various factors which may affect an optimal maintenance policy. . It is noted that for a series system there exist some shut-off rules. This shut-off rule is used in Barlow and Proshan (1975). Obviously, it is practical and can be applicable in other system configurations. 
Fig. 1. Maintenance policy and its influence factors.

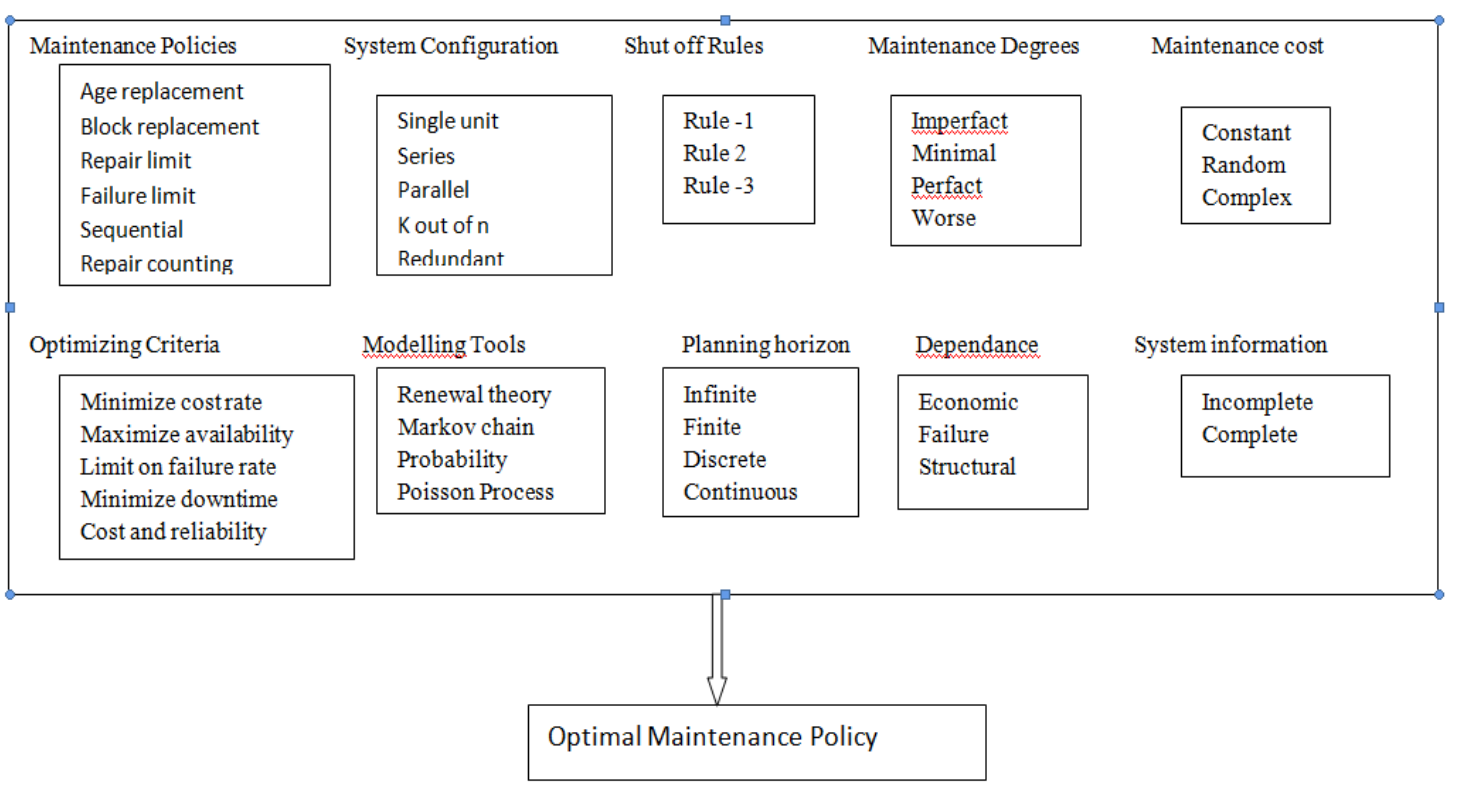

Hudes (1979) and Khalil (1985) discuss various shut-off rules. Besides, it is worthwhile to mention the following points:

(1).. All these methods for a single-unit system will be the basis for the analysis of a multicomponent system.

2. Most optimal maintenance models in the literature use the optimization criterion: minimizing system maintenance cost rate but ignoring reliability performance. The optimal maintenance policy must be based on not only cost rate but also reliability measures. It is important to note that for multicomponent systems minimizing system maintenance cost rate may not imply maximizing the system reliability measures. Therefore, to achieve the best operating performance, an optimal maintenance policy needs to consider both maintenance cost and reliability measures simultaneously.

3. In most existing literature on maintenance theory, the maintenance time is assumed to be negligible. This assumption makes availability, MTBSF and MTBSR modeling impossible or unrealistic. Considering maintenance time will result in realistic system reliability measures.

4. The structure of a system must be considered to obtain optimal system reliability performance and optimal maintenance policy.

\section{CONCLUSION:}

In this paper, It is tried to cover as much as possible different maintenance related papers and particularly in the context of maintenance policies. However, those papers which are not included were either considered not to bear directly on the topic of this survey or were inadvertently overlooked. The apology to both the researchers and readers if any relevant papers have been omitted are manifested. The paper will definitely help the people to have a basic knowledge about the maintenance policies and which policy will be appropriate to their organization 
International Journal of Software Engineering \& Applications (IJSEA), Vol.2, No.3, July 2011

\section{REFERENCES}

(1) Gertsbakh I. Reliability theory with applications to preventive maintenance. Springer, Berlin: 2000,pp 23-190

(2) Barlow RE, Proschan F. "Mathematical theory of reliability"John Wiley and sons, Sydney1967;pp 46-117

(3) Badı'a FG, Berrade MD, Campos CA. Optimization of inspection intervals based on cost. J Appl Probab 2001; vol 38:872-81.

(4) Badı́a FG, Berrade MD, Campos CA. Maintenance and monitoring policy under unrevealed failures. Proceedings of the 10th International Symposium on Applied Stochastic Models and Data Analysis, June 12-15, 2001, vol.1 pp.142-147

(5) .Nakagawa T. Periodic inspection policy with preventive maintenance. Naval Res Logist Quart 1984, vol 31:pp33-40.

(6) Nakagawa T, Yasui K. Periodic-replacement models with threshold levels, IEEE Transaction on Reliability 1991;vol: 40:pp: 395-407.

(7) Vaurio JK. Optimization of test and maintenance intervals based on risk and cost ,Reliability Engineering andSystem Safety 1995;vol:49: pp23-26.

(8) Vaurio JK. On time-dependent availability and maintenance optimization of standby units under various maintenance policies. Reliability Engineering and System Safety 1997;vol 56:pp 7989.

(9) Ross S. Stochastic processes, 2nd edition. Wiley: New York; 1996.pp 11-45

(10) Vaurio JK. Availability and cost functions for periodically inspected preventively maintained units. Reliability Engineering and System Safety 1999; vol 63: pp133-140.

(11) Ushakov I, "Reliability: past, present, future," Recent Advances in Reliability Theory: Methodology, Practice, and Interface, 2000; Birkhäuser, Boston,pp 3-14.

(12) R. Barlow and F. Proschan, Mathematical Theory of Reliability, 1965; Wiley, New York pp 10231

(13). R. Barlow, "Mathematical reliability theory from the beginning to the present time," Proceedings. International. Conference Mathetical .Methods in Reliability., Newyork , 2002.

(14).H.E. Blanton, R.M. Jacobs, "A survey of techniques for analysis and prediction of equipment and reliability", IEEE Tranactionon on. Reliability Athens., July 1962, pp.18-35.

(15) W. Weibull, "A statistical theory of the strength of materials", Ing. VetenskapsAkad. Handl.,U.S.A. no. 151, 1939,pp.293-297.

(16) B. Epstein, M. Sobel, "Life testing", J. Amer. Stat. Assoc., vol. 48, no. 263, 1953, pp. 486-502.

(17) H.E. Daniels, "The statistical theory of the strength of bundles of threads", Proc. Roy. Soc. London, vol. 183, 1945, pp. 405-435.

(18) B. Epstein, "Application of the theory of extreme values in fracture problems", J. Amer. Stat. Assoc., vol. 43,1948, pp. 403-412.

(19) W. Weibull, "A statistical distribution function of wide applicability", J. Applied Mech., vol. 18, 1951, pp. 293-297.

(20) D.J. Davis, "An analysis of some failure data", J. Amer. Stat. Assoc., vol. 47, 1952, pp. 113150.

(21) J.H.K. Kao, "A new life-quality measure for electron tube", IRE Trans. Rel. and Quality Ctrl., PGRQC- 7, 1956, pp. 1-11.

(22) J.H.K. Kao, "Computer methods for estimating Weibull parameters in reliability studies", IRE Trans. Rel. and Quality Ctrl., PGRQC-13, 1958, pp. 15-22.

(23) R.J. Buehler, "Confidence intervals for the product of two binomial parameters", J. Amer, Stat. Assoc., vol. 52, 1957, pp. 482-493.

(24) Z.W. Birnbaum, S.C. Saunders, "A statistical model for life-length of materials", J. Amer. Stat. Assoc., vol. 53, no. 281, 1958, pp. 151-160.

(25) G.R. Herd, "Some statistical concepts and techniques for reliability analysis and prediction", Proc. Natl. Symp. Rel. and Quality Ctrl., Jan 1959, pp. 126-136. 
International Journal of Software Engineering \& Applications (IJSEA), Vol.2, No.3, July 2011

(26) R.F. Tate, "Unbiased estimation: Functions of location and scale parameters", Ann. Math. Stat., vol. 30, no.2, 1959, pp. 341-366.

(27) D.R. Cox, "On the number of Renewals in a Random Interval," Biometrika, vol. 47, issue 3/4, Dec. 1960, pp. 449-452.

(28) M. Zelen, M.C. Dannemiller, "The robustness of life testing procedures derived from the exponential distribution", Technometrics, vol. 3, no. 1, 1961, pp. 29-49.

(29) J.E. Nylander, "Statistical distributions in reliability", IRE Trans. Rel. and Quality Ctrl., RQC11, July 1962, pp. 43- 53.

(30) J.F. Shortle, M.B. Mendel, "Physical foundations for lifetime distributions", Proc. System and Bayesian Rel.2001,pp. 257-266.

(31) G.S. Watson and W.T. Wells, "On the possibility of improving the mean useful life of items by eliminating thosewith short lives", Technometrics, vol. 3, 1961, pp. 281-198.

(32) R.E. Barlow, A.W. Marshall, F. Proschan, "Properties of probability distributions with monotone hazard rate", Ann. Math. Stat., vol. 34, 1963, pp.375-389.

(33) R.E. Barlow, A.W. Marshall, "Bounds for distributions with monotone hazard rate, I and II", Ann. Math.Stat., vol. 35, 1964, pp. 1234-1274.

(34) S.M. Ross, Introduction to Probability Models with Optimization Applications, 1972; Academic Press, New York.

(35) H. Block, T.H. Savits, "The IRFA closure problem", Ann. Prob., 4, 1976, pp. 1030-1032.

(36) S.A. Meltzer, "Designing for reliability", IRE Trans Rel. and Quality Ctrl., PGRQC-8, Sept 1956, pp. 36-43.

(37) H.E. Blanton, "Reliability-sensitivity- function analysis", Electronic Design, vol. 6, Feb 1958.

(38) F.E. Dreste, "Statistics: Key to reliable military electronic design", Military Electronics, vol. 6, Mar. 1959, pp.4, 6, 8.

(39) F.E. Dreste, "Circuit design concepts for high reliability", Proc. Natl. Symp. Rel. and Quality Ctrl., Jan 1960,pp. 121-133.

(40) G.P. Steck, "Upper confidence limits for the failure probability of complex networks", Sandia CorporationResearch Report, SC-4133(TR), 1958.

(41) A. Madansky, "Uses of tolerance limits in missile evaluation", Proc. Stat. Techniques in Missile EvaluationSymp., Aug 1958.

(42) J.R. Rosenblatt, "Confidence limits for the reliability of complex systems", Stat. Theory of Rel., University ofWisconsin Press, Madison, Wisconsin, 1963, pp. 115-148.

(43) M.V. Johns, G.J. Lieberman, "An exact asymptotically efficient confidence bound for reliability in thecase of the Weibull Distribution", Technometrics, vol. 8, 1966, pp. 135-175.

(44) D.R. Thoman, L.J. Bain, C.E. Antle, "Maximum Likelihood Estimation, Exact Confidence Intervals forReliability, and Tolerance Limits in the Weibull Distribution", Technometrics, vol. 12, 1970, pp. 363-371.

(45) H.F. Martz, B.S. Duran, "Comparison of three methods for calculating lower confidence limits on systemreliability using component data", IEEE Trans. Rel., vol. R- 34, no. 2, 1985.

(46) A.J. Lotka, "A contribution to the theory of selfrenewing aggregates with special reference to industrialreplacement", Ann. Math. Stat., vol. 10, 1939, pp. 1-25.

(47) N.R. Campbell, "The replacement of perishable members of a continually operating system", $J$. Roy. Stat. Soc., vol. 7, 1941, pp. 110-130.

(48) W. Feller, "On the integral equation of renewal theory", Ann. Math. Stat., vol. 12, 1941, pp. 243-267.

(49) D. Blackwell, "A renewal theorem", Duke Math. J., vol. 15, 1948, pp. 145-150.

(50) J.L. Doob, "Renewal theory from the point of view of the theory of probability", Trans. Amer. Math. Soc., 63, 1948, pp. 422-438.

(51) W. Feller, "Fluctuation theory of recurrent events", Trans. Amer. Math. Soc., vol. 67, 1949, pp. 98-119.

(52) D.R. Cox, W.L. Smith, "A direct proof of a fundamental theorem of renewal theory", Skand. Aktuar., 36,1953, pp. 139-150.

(53) W.L. Smith, "Asymptotic renewal theorems", Proc. Roy. Soc. Edin., A, 64, 1954, pp. 9-48. 
International Journal of Software Engineering \& Applications (IJSEA), Vol.2, No.3, July 2011

(54) W. Feller, Introduction to Probability Theory and its Applications, 2nd ed., 1957; Wiley, New York.

(55) W.L. Smith, "Renewal theory and its ramifications", J. Roy. Stat. Soc., Ser. B, vol. 20, no. 2 , 1958, pp. 243-302.

(56) W.L. Smith, "On the cumulants of renewal processes," Biometrika, vol. 46, issue 1/2, June 1959, pp. 1-29.

(57) R.E. Barlow, L.C. Hunter, "Mathematical models for system reliability", Sylvanica Electronic Defense Labs., Rept. No. EDL-E35, Aug 1959.

(58) R.E. Barlow, L.C. Hunter, "Mathematical models for system reliability, part II", The Sylvania Technologist, vol. 13, 1960, pp. 55-65.

(59) D.R. Cox, Renewal Theory, 1962; Wiley, New York. 50. G.S. Watson and M.R. Leadbetter, "Hazard Analysis.I," Biometrika, vol. 51, June 1964, pp. 175-184.

(60) B.V. Gnedenko, Y.K. Belyaev, A.D. Solovyev, Math. Methods in Reliability Theory, 1969; Academic Press, New York. (Please note that this book was published in 1965 in Russia)

(61) Z.W. Birnbaum, "On a use of the Mann-Whitney Statistic", Proc. Berkeley Symp. Math. Stat. and Prob.,University of California Press, Los Angeles, vol. 1, 1955, pp. 13-17.

(62) Z.W. Birnbaum, J.D. Esary, S.C. Saunders, "Multicomponent systems and structures and their reliability",Technometrics, vol. 3, Feb 1961, pp. 55-77.

(63) J.D. Esary, F. Proschan, "Coherent structure of nonidentical components", Technometrics, no. 5, 1963, pp. 191-209.

(64)Z.W. Birnbaum, J.D. Esary, "Modules of coherent binary systems", J. SIAM, vol. 13, 1965, pp. 444-462.

(65)Z.W. Birnbaum, J.D. Esary, A.W. Marshall, "Stochastic characterization of wear out for components andsystems", Ann. Math. Stat., 37, 1966, pp. 816-825

(66)Z.W. Birnbaum, "On the importance of different components in multicomponent system," MultivariateAnalysis, II, 1969; Academic Press, New York, pp.581-592.

(67) A. Satyanarayana, A. Prabhakar, "New topological formula and rapid algorithm for reliability analysis of complex networks", IEEE Trans. Rel., R-27, 1978, pp. 82-100.

(68) A. Satyanarayana, M.K. Chang, "Network reliability and the factoring theorem", Networks, 13, 1983, pp. 107-120.

(69) A. Bendell, J. Ansell, "The incoherency of multistate coherent system", Rel. Eng., vol. 8, 1984, pp. 165-178.

(70) A.B. Huseby, "Domination Theory and the crapo beta-invariant", Networks, 19, 1989, pp. 135149.

(71) J.C. Fu, M.V. Koutras, "Reliability bounds for coherent structures with independent components", Stat. andProb. Letters, vol. 22, 1995, pp. 137-148.

(72) S. Tsitmidelis, M.V. Koutras, V. Zissimopoulos, "Evaluation of reliability bounds by genetic algorithm", Proc.Math. Methods in Rel., 2002.

(73) M.V. Boutsikas, M.V. Koutras, "Generalized reliability bounds for coherent structures", J. of Applied Prob.,vol. 37, 2000, pp. 778-794.

(74) T. Inagaki, E.J. Henley, "Probabilistic evaluations of prime implicants and top events for noncoherent systems",IEEE Trans. Rel., vol. R-29, no. 5, Dec. 1980, pp. 361-367.

(75) P.S. Jackson, "On the s-importance of elements and prime implicants of noncoherent systems", IEEE Trans. Rel., vol. R-32, no. 1, Apr. 1983, pp. 21-25.

(76) J.D. Andrews, S. Beeson, "Birnbaum's measure of component importance for noncoherent systems", IEEE Trans. Rel., vol. 52, no. 2, June 2003, pp. 213-219.

(77) T.F. Oltorik, "Reliability analysis using flowgraphs", Air Force Institute of Technology, USGRR Document, no. AD 420-047, Aug 1963.

(78) W.W. Haap, "Application of flowgraph techniques to the solution of reliability problems", $J$. Physics of failure in Electronics, US Department of Commerce Office of Technical Services AD-434/329, 1964, pp. 375-423.

(79) E. Dolozza, "System states analysis and flowgraph diagrams in reliability", IEEE Trans. Rel., R15, 1966, pp.383-394. 
International Journal of Software Engineering \& Applications (IJSEA), Vol.2, No.3, July 2011

(80) M.M. Kleinerman, G.H. Weiss, "On the reliability of networks", Proc. Natl. Electronics Conf., vol. 10, 1954, pp.128-136.

(81) E. Blanton, "Reliability-Prediction technique for use in design of complex systems", IRE Natl. Convention Record, pt. 10, 1957, pp. 68-79.

(82) http://www.newhousenews.com/archive/macpherson0 21103.html retrived on 10.08.2006

(83) C.W. Holtzman, Jr., W.E. Marshall, "A new method of communication between engineering and mathematicianaids system reliability prediction", Proc. Natl. Symp. Rel. and Quality Ctrl., Jan 1960, pp. 403-408.

(84) P. Chatterjee, "Modularization of fault trees: A method to reduce cost of analysis", SIAM Rel. and Fault Tree Analysis, 1975, pp. 101-137.

(85) A. Rosenthal, "Decomposition methods for fault tree analysis", IEEE Trans. Rel., vol. 43, June 1980, pp. 136-138.

(86) J.B. Dugan, S.J. Bavuso, M.A. Boyd, " Dynamic fault tree models for fault tolerant computer systems", IEEE Trans. Rel., vol. 41, no. 3, Sept 1992, pp. 363-377.

(87) J.B. Dugan, S.J. Bavuso, M. Boyd, "Fault trees and Markov models for reliability analysis of fault tolerantsystems", Rel. Eng. and System Safety, vol. 39, 1993, pp. 291- 301.

(88) R. Gulati, J.B. Dugan, "A modular approach for analyzing static and dynamic fault trees", Proc. RAMS, 1997.

(89) O. Coudert, J.C. Madre, "Fault tree analysis: 10^20 prime implicants and beyond", Proc. RAMS, 1993, pp. 240-245.

(90) S.A. Doyle, J.B. Dugan, "Dependability assessment using binary decision diagrams", Proc. IEEE Int. Symp. Fault- Tolerant Computing, FTCS-25, June 1995.

(91) Y. Dutuit, A. Rauzy, "A linear-time algorithm to find modules in fault trees", IEEE Trans. Rel., Sept. 1996.

(92). H.F. Martz, R.G. Almond, "Using higher-level failure data in fault tree quantification", Rel. Eng. and System Society, 1997, pp. 29-42.

(93) A. Anand, A.K. Somani, "Hierarchical analysis of fault trees with dependencies, using decomposition", Proc.RAMS, Jan 1998, pp. 69-75.

(94) R. Manian, D. Coppit, K.J. Sullivan, J.B. Dugan, "Bridging the gap between systems and dynamic fault treemodels", Proc. RAMS, Jan 1999, pp. 105-111.

(95) C.W. Griffin, "Introducing the fault tree as a tool for nuclear safety analysis", Trans. Amer. Nuclear Soc., vol. 9, no. 1, 1966, pp. 157.

(96) J.D. Andrews, "The use of Not logic in fault tree analysis", Qual. Rel. Eng., vol. 17, 2001, pp. 143-150.

(97) S.V. Tsitmidelis, S.V. Zissimopoulos, M.V. Koutras,"Fault tree analysis via set cover model", EUROGEN 2001,Athens, Greece.

(98) I.A. Papazoglou, "Mathematical foundations of event trees", Rel. Eng. and System Safety, vol. 61, 1998, pp. 169-183

(99) J.D. Andrews, S. Dunnett, "Improving accuracy in event tree analysis", Proc. Foresight and Precaution, Proc.ESREL 2000, SARS and SRA-Europe Annual Conf., May 2000.

(100) J.D. Andrews, S. Dunnett, "Event tree analysis using binary decision diagrams", IEEE Trans. Rel., vol. R-49, no.2, June 2000, pp. 230-239.

(101) A.N. Kolmogorov, "A number of target hits by several shots and general principles of effectiveness ofgunfire", Proc. Moscow Inst. Math., issues 12, 1945.

(102) R.O. Frantik, "The determination application and limitations of circuit reliability equations", Sandia Corp.,report no. SC-3288(TR), April 1954.

(103) L. Takács, "On a sojourn time problem in the theory of stochastic processes," Trans. Amer. Math. Soc., vol. 93, issue 3, Dec. 1959.

(104) E.A. Elsayed, A. Zebib, "A repairable multistate device", IEEE Trans. Rel., R-28, 1979, p. 81-82.

(105) L.D. Bodin, "Approximation of system reliability using a modular decomposition", Technometrics, vol. 12, no.2, 1970, pp. 335-344. 
International Journal of Software Engineering \& Applications (IJSEA), Vol.2, No.3, July 2011

(106) A.T. Bharucha-Reid, Elements of the Theory of Markov Processes and their Applications, 1960; McGraw-Hill, New York

(107) J. Keilson, A. Kooharian, "On time dependent queuing processes", Ann. Math. Stat., vol. 31, 1960.

(108) D.M. Brender, M. Tainiter, "A Markovian model for predicting the reliability of an electronic circuit from data on component drift and failure", IRE Intl. Convention Record, 1961, pt. 6, pp. 230-241.

(109) I.B. Pogozhev, "Estimation of deviation of failure flow in multi-use equipment from Poisson process",Cybernetics in Service for Communism, vol. 2, Energiya, Moscow, 1964.

(110) A.D. Solov'yev, "Reliability and queueing theory: standby with rapid renewal," Eng. Cybernetics, no.1, 1970, pp. 49-64.

(111) A.D. Solov'vey, "Redundancy with fast repair", Eng. Cybernetics, no. 1, 1970.

(112) B. Ouhbi, N. Limnios, "Estimation of kernel, availability and reliability of semiMarkov systems", Proc.Stat. and Prob. Methods in Rel., 1999.

(113) B. Ouhbi, N. Limnios, "Non-parametric estimation for semi-Markov processes based on its hazard rate", Stat. Inf. Stoc. Proc., vol. 2, 1999, pp. 151-173.

(114) R.M. Fricks, K.S. Trivedi, "Importance analysis with Markov Chains", Proc. Rel. and Main. Symp., 2003, pp. 89-95.

(115) Y. Lefebvre, "Using equivalent failure rates to assess the unavailability of an ageing system", Proc. Rel. and Main. Symp., 2003, pp. 82-88.

(116) E.F. Moore, C.E. Shannon, "Reliable circuits using less reliable relays", J. of the Franklin Institute, vol. 262,1956, Pt. I, pp. 191-208, and Pt II, pp. 281-297. (

(117) B.V. Gnedenko, "On duplication with renewal", Eng. Cybernetics, Newyork no. 5, pp -282-2971964.

(118) C.R. Gates, "The reliability of redundant systems", JPL-California Inst. Of Tech. Pasadena, CA, Memo 20-76,Aug 1952.

(119) H. Mine, "Reliability of physical system", IRE Trans. Information Theory, IT-S (Special Supplement), 1959,pp. 138-150.

(120) F. Mosteller, R.E. Rourke, G.B. Thomas, Jr., Probability with statistical applications, 1961; Addison-Wesley, Reading.

(121) I.I. Bazovsky, Relability Theory and Practice, 1961; Prentice Hall, Englewood Cliffs.

(122) H.F. Martz, R.A. Waller, Bayesian Reliability Analysis, 1982; Wiley, New York.

(123) H.F. Martz, R.A. Waller, E.T. Fickas, "Bayesian reliability analysis of series systems of binomial subsystemsand components", Technometrics, vol. 30, 1988, pp. 143-154.

(124) H.F. Martz, R.A. Waller, "Bayesian reliability analysis of complex series/parallel systems of binomialsubsystems and components", Technometrics, vol. 32, 1990, pp. 407-416.

(125) F.L. Hulting, J.A. Robinson, "The reliability of a series system of repairable subsystems: a Bayesian approach",Naval Research Logistics, vol. 41, 1994, pp. 483-506.

(126) W.J. Kerscher III, J.M. Booker, T.R. Bement, M.A. Meyer, "Characterizing reliability in a product/process design -assurance program", Proc. RAMS, 1998, pp. 105-112.

(127) S.L. Firstman, "Monte Carlo models for estimating reliability: An exploratory analysis", The Rand Corp., Report no. RM2149, ASTIA Doc. No. AD213036, June 1958.

(128) Y.K. Belyaev, T.N. Dugina, E.V.Chepurin, "Computation of lower confidence limit for the complexsystem reliability", Eng. Cybernetics, no's 2 \& 3, 1967.

(129) F. Moskowitz, J. McLean, "Some reliability aspects of system design", IRE Trans. Rel. and Quality Ctrl., vol. 8, 1956, pp. 7-35.

(130) R. Gordon, "Optimum component redundancy for maximum system reliability", Operations Res., vol. 5, 1957,pp. 229-243.

(131) R. Bellman and S. Dreyfus, "Dynamic programming and reliability of multicomponent devices", Operations Res., vol. 6, 1958, pp. 200-206.

(132) G. Black, F. Proschan, "On optimal redundancy", Operations Res., vol. 7, no. 5, 1959, pp. 581-588. 
(133) J.D. Kettelle, "Least-cost allocation of reliability investment", Operations Res., vol. 10, no. 2, 1962.

(134) R.E. Barlow, L.C. Hunter, F. Proschan, "Optimum redundancy when components are subject to two kinds offailure", J. SIAM, vol. 11, 1963, pp.64-73.

(135) F. Proschan, T. Bray, "Optimum redundancy under multiple constraints", Operations Res., vol. 13, no. 5, 1965.

(136) F.A. Tillman, H. Ching-Lai, W. Kuo, Optimizationof System Reliability, 1980; Marcel Dekker, New York.

(137) K.E. Portz, H.R. Smith, "Methods for the determination of reliability", IRE Trans. Rel. and QualityCtrl., vol. 11, Aug 1957, pp. 65-73.

(138) J.P. Lipp, "Topology of switching elements vs. reliability", IRE Trans. Rel. and Quality Ctrl., vol. 10, June1957, pp. 21-33.

(139) B.J. Flehinger, "Reliability improvement through redundancy at various system levels", IBM J. of RnD, issue 2,1958, pp. 148-158.

(140) J.L.Philipson, "Operational reliability model for a reconnaissance system", IRE Natl. Convention Record, pt. 6,1959, pp. 79-88.

(141) M.I. Kaufmann, R.A. Kaufmann, "Predicting reliability", Machine Design, Aug 1960, pp. 178-184.

(142) E. Cramer, U. Kamps, "Sequential k-out-of-n systems", http://www.math.unioldenburg.de/preprints/get/source/Hb.pdf, Feb 2000.

(143) W.J. Kerscher III, J.M. Booker, M.A. Meyer, R.E. Smith, "PREDICT: A case study, using fuzzy logic", Proc.RAMS, 2003, pp. 188-195. "PREDICT: A case study, using fuzzy logic", Proc. RAMS, 2003, pp. 188-195.

(144) M. Marseguerra, E. Zio, M. Ammaturo, V. Fontana, "Predicting reliability via neural networks", Proc. RAMS,2003, Tampa, Florida, pp. 196-201.

(145) Abdel-Hameed, M., 1987a. An imperfect maintenance model with block replacements. Applied Stochastic Models and Data Analysis 3, 63-72.

(146) Abdel-Hameed, M., 1987b. Inspection and maintenance policies of devices subject to deterioration. Advances in Applied Probability 10, 917-931.

(147) Abdel-Hameed, M., 1995. Correction to: "Inspection and maintenance policies of devices subject to deterioration'. Advances in Applied Probability 27 (2), 584.

(148) Archibald, T.W., Dekker, R., 1996. Modified block-replacement for multiplecomponent systems. IEEE Transactions on Reliability 45 (1), 75-83.

(148) Asher H. Fein gold H.,1984Repairable systems reliability,. Marcel Dekker, New York.

(149) . Assaf, D., Shanthikumar, J.G., 1987. Optimal group maintenance policies with continuous and periodic inspections. Management Science 33, 1440-1450.

(150) Aven, T., 1983. Optimal replacement under a minimal repair strategy - a general failure model. Advances in Applied Probability 15 (1), 198-211.

(151) Aven, T., Jensen, U., 1999. Stochastic Models in Reliability,Applications of Mathematics, vol. 41, Springer, New York.

(152) Balaban, H.S., Singpurwalla, N.D., 1984. Stochastic properties of a sequence of interfailure times under minimal repair andunder revival. In:

(153) Abdel-Hameed, M., Cinlar, E., Quinn, J. (Eds.), Reliability Theory and Models. Academic Press, Orlando, FL, pp. 65-80.

(154) Barlow, R.E., Hunter, L.C., 1960. Optimum preventive maintenance policies. Operations Research 8, 90-100.

(155) Barlow, R.E., Proshan, F., 1965. Mathematical Theory of Reliability. Wiley, New York.

(156) Barlow, R.E., Proshan, F., 1975. Statistical Theory of Reliability and Life Testing. Holt, Rinehart \& Winston, New York.

(157) Beichelt, F., 1976. A general preventive maintenance policy. Mathematische Operationsforschung und Statistik Series,Statistics 7, 927-932. 
(158) Beichelt, F., 1978. A new approach to repair limit replacement policies. In: Transactions of the Eighth Prague Conference on Information Theory, Statistical Decision Functions,Random Processes, vol. C, Prague, pp. 31-37.

(159) Beichelt, F., 1981a. A generalized block-replacement policy. IEEE Transactions on Reliability R 30 (2), 171-173.

(160) Beichelt, F., 1981b. Replacement policies based on system age and maintenance cost limits. Mathematische Operationsforschung und Statistik Series, Statistics 12 (4), 621-627.

(161) Beichelt, F., 1982. A replacement policy based on limits for the repair cost rate. IEEE Transactions on Reliability R 31 (4),401-402.

(162) Beichelt, F., Fischer, K., 1980. General failure model applied to preventive maintenance policies. IEEE Transactions on Reliability R 29(1), 39-41.

(163) Berg, M., 1976. A proof of optimality for age replacement policies. Journal of Applied Probability 13, 751-759.

(164) .Berg, M., 1976. Optimal replacement policies for two-unit machines with increasing running costs - I. Stochastic Processes and Applications 5, 89-106.

(165) .Berg, M., 1978. General trigger-off replacement procedures for two-unit systems. Naval Research Logistics 25 (March),15-29.

(166) Berg, M., Epstein, B., 1976. A modified block replacement policy. Naval Research Logistics 23, 15-24.

(167) Berg, M., Epstein, B., 1978. Comparison of age, block, and failure replacement. IEEE Transactions on Reliability R 27(1), 25-29.

(168) Bergman, B., 1978. Optimal replacement under a general failure model. Advances in Applied Probability10 (2),431-451.

(169) Block, H.W., Borges, W.S., Savits, T.H., 1985. Age dependent minimal repair. Journal of Applied Probability 22,370-385.

(170) Block, H.W., Borges, W.S., Savits, T.H., 1988. A general age replacement model with minimal repair. Naval Research Logistics 35 (5), 365-372.

(171) Block, H.W., Langberg, N.A., Savits, T.H., 1990. Comparisons for maintenance policies involving complete and minimal repair. in: Henry W.B., Allan R.S., Thomas H.S. (Eds.),Proceedings of the Symposium on Dependence in Proba-bility and Statistics. Somerset, Pennsylvania, August 1-5, 1987; IMS Lecture Notes Monograph Ser. 16, Inst. Math.Statist., Hayward, CA.

(172) Block, H.W., Langberg, N.A., Savits, T.H., 1993. Repair replacement policies. Journal of Applied Probability 30 (1),194-206.

(173) Boland, P.J., 1982. Periodic replacement when increasing minimal repair costs vary with time. Naval ResearchLogistics 29, 541-546.

(174) Boland, P.J., El-Neweihi, E., 1998. Statistical and information based (physical) minimal repair for k out of $\mathrm{n}$ systems. Journal of Applied Probability 35 (3), 731-740.

(175) Boland, P.J., Proschan, F., 1982. Periodic replacement with increasing minimal repair costs at failure. Operations Research 30, 183-1189.

(176) Boland, P.J., El-Neweihi, E., Proschan, F., 1991. Stochastic order for inspection and repair policies. The Annals of Applied Probability 1 (2), 207-218.

(177) Canfield, R.V., 1986. Cost optimization of periodic preventive maintenance. IEEE Transactions on Reliability R 35 (1),78-81.

(178) Chan, J.K., Shaw, L., 1993. Modeling repairable systems with failure rates that depend on age and maintenance. IEEE Transactions on Reliability 42, 566-570.

(179) Chan, P.K.W., Downs, T., 1978. Two criteria for preventivemaintenance. IEEE Transactions on Reliability R 27, 272-273. 